\title{
A presença/ausência da produção marxiana e de Manacorda nos currículos de pedagogia das universidades federais
}

\author{
The presence / absence of marxian production and \\ management in the pedagogy curriculums of the federal \\ universities
}

\author{
Marco Antonio de Oliveira Gomes \\ Departamento de Fundamentos da Educação, Universidade Estadual de Maringá \\ Maringá, Brasil, marcooliveiragomes@yahoo.com.br
}

\section{Resumo}

Este artigo objetiva analisar a presença e ausência dos textos de Marx e Manacorda nos cursos de pedagogia de universidades federais. Assim, procura desvelar as orientações epistemológicas presentes na área de fundamentos da educação. Para realização do trabalho foram analisados os projetos político pedagógicos e a bibliografia disponibilizadas nos endereços eletrônicos das instituições. Tendo como princípio norteador o referencial teórico marxista, foram utilizados os seguintes autores: Gramsci (1982), Manacorda (1996, 2007), Marx (1984, 2007), Frigotto (2003), entre outros. A ausência de uma epistemologia alicerçada no materialismo histórico e dialético explica-se pela hegemonia material da burguesia que se traduz em um modelo de formação de professores que esvazia o conhecimento.

Palavras chave: Pedagogia. Universidades Federais. Fundamentos da Educação. Marx. Manacorda.

\begin{abstract}
This article aims to analyze the presence and absence of the texts of Marx and Manacorda in the courses of pedagogy of federal universities. Thus, it seeks to unveil the epistemological orientations present in the area of foundations of education. For the accomplishment of the work the political pedagogical projects and the bibliography made available in the electronic addresses of the institutions were analyzed. The following authors were used as guiding principles: Gramsci (1982), Manacorda (1996, 2007), Marx (1984, 2007), Frigotto (2003), among others. The absence of an epistemology based on historical and dialectical materialism is explained by the material hegemony of the bourgeoisie, which translates into a model of teacher training that empties knowledge.
\end{abstract}

Keywords: Pedagogy. Federal Universities. Fundamentals of Education. Marx. Manacorda. 


\section{Introdução}

O estudo aprofundado sobre a presença da produção marxiana e de Manacorda na formação do pedagogo no Brasil é uma tarefa árdua, ainda por ser realizada, em que pese os trabalhos já publicados. Assim, o presente estudo não apresenta uma temática original, mas pretende analisar os resultados de uma abrangente investigação desenvolvida em torno dos cursos de Pedagogia ofertados em Universidades Federais, buscando desvelar as orientações epistemológicas presentes na área de fundamentos da educação, que se encontram sob intensa disputa, quer pela função que as disciplinas que a compõem exercem na formação do futuro educador, quer pelas funções que muitos imaginam que poderiam exercer.

Delimitando de forma mais precisa, foram analisadas disciplinas que compõem o núcleo curricular voltado para os fundamentos filosóficos, sociológicos e históricos da educação, acrescidas de disciplinas optativas, cuja denominações indicavam a possibilidade de contribuição de uma epistemologia marxista. Desse modo, foram analisadas 56 disciplinas presentes em 24 cursos ofertados em universidades federais.

O levantamento dos dados disponíveis indica que não apenas Manacorda, mas a epistemologia alicerçada no materialismo histórico e dialético encontra-se ausente da grande maioria dos cursos de Pedagogia das Universidades Federais. A ausência do pensamento marxista não é um fenômeno em si mesmo, entretanto deve ser compreendido como manifestação inseparável da situação histórica que o produz. Não é demasiado lembrar que em uma sociedade dividida em classes sociais existe a tendência a universalizar o pensamento segundo os interesses da classe dominante.

As ideias da classe dominante são em cada época, as ideias dominantes, isto é, a classe que é a força material dominante da sociedade é, ao mesmo tempo, sua força espiritual dominante. A classe que tem à sua disposição os meios de produção material dispõe, ao mesmo tempo, dos meios de produção espiritual, o que faz com que a ela sejam submetidos ao mesmo tempo e em média, as ideias daqueles aos quais faltam os meios de produção espiritual. (...) Os indivíduos que constituem a classe dominante possuem, entre outras coisas, também consciência e, por isso, pensam; na medida que dominam como classe e determinam todo o âmbito de uma época histórica, é evidente que o façam em toda a sua extensão e, consequentemente, entre outras coisas, dominem como pensadores, como produtores de ideias; que regulem a produção e a distribuição das ideias de seu tempo e que suas ideias sejam, por isso mesmo, as ideias dominantes da época. (Marx \& Engels, 1984, pp. 26-27)

As contribuições de Marx e Engels auxiliam no esclarecimento sobre a hegemonia da perspectiva burguesa sobre as relações sociais, tomando como raiz 
para sua compreensão a dinâmica da produção da riqueza material. A apropriação privada dos meios de produção por uma classe desdobra-se para o conjunto das relações dos indivíduos e das classes sociais. Assim, as ideias reinantes na sociedade burguesa, incluindo aquelas sobre a educação e a formação do pedagogo, são as da burguesia pelo fato de dominar os meios materiais de produção.

Não por acaso, as perspectivas dominantes no campo da educação identificam-se com as bandeiras pós-modernas, que podem ser sintetizadas na negação das lutas de classes, da racionalidade e objetividade. Como desdobramento desta perspectiva, verifica-se uma nova pauta de estudos que priorizam objetos efêmeros que não auxiliam a compreensão das relações sociais entre o homem.

Diante da hegemonia da perspectiva pós-moderna, que não pode ser desvinculada da crise estrutural do capitalismo, quanto mais desconectada das relações materiais que engendram o fenômeno histórico, maior será a relevância da pesquisa. Observa-se a negação da realidade como objetividade ou a negação da possibilidade de apreender o real. Em outras palavras, trata-se de um movimento de legitimação da ordem política e social vigente por meio da negação das possibilidades de sua superação.

Isto posto, um tema tão importante e controverso quanto a presença/ausência da epistemologia marxiana e da produção de Manacorda nos cursos de Pedagogia só pode ser abordada de forma parcial e lacunar nos limites de um artigo, o que não impede que seja tratado com rigor científico e que auxilie a compreensão do real.

Assim, buscando manter a coerência com o método de Marx, partimos dos dados empíricos concretos materializados nos projetos de curso para buscar por meio da análise a compreensão do fenômeno inserido em um quadro de carências de ordem econômica e na formação de professores da educação básica.
A questão de saber se ao pensamento humano cabe alguma verdade objetiva não é uma questão da teoria, mas uma questão prática. Na prática tem o homem de provar a verdade, isto é, na realidade o poder, na citerior de seu pensamento. A disputa acerca da realidade ou não realidade de um pensamento que se isola da prática é uma questão puramente escolástica. (Marx \& Engels, 2007, p. 537)

Diante do exposto, assumimos como pressuposição fundamental da epistemologia marxiana uma diferença essencial e definitivamente central, entre o fato comprovável e a ficção, entre declarações e/ou documentos baseados em evidências e sujeitas a evidenciação e aquelas que não o são. $O$ método de Marx e Engels toma a sociedade burguesa como uma totalidade concreta. Não se trata de um amontoado de partes que se integram, mas um sistema dinâmico marcado por 
relações articuladas que são constituídas de forma histórica e que se explicam estruturalmente.

\begin{abstract}
Seu objetivo é reproduzir idealmente o movimento constitutivo da realidade social, que se expressa de formas econômicas, políticas e culturais, mas que se extravasa todas elas. Por isso, a análise da organização da economia (a crítica da economia política) é o ponto de irradiação para análise da estrutura de classes e da funcionalidade do poder (a crítica do Estado) e das formulações jurídico-políticas (a crítica da ideologia). A pesquisa destas dimensões da realidade (social) remete de uma a outra - assim, a análise do movimento das classes; donde, na teoria marxiana, a ausência de qualquer viés 'fatorialista' (a predominância abstrata do 'fator econômico' ou semelhante). (Netto Paulo, 1998, p. XXIX).
\end{abstract}

A partir da epistemologia marxiana, é possível compreender que a educação e os profissionais que trabalham e militam, direta ou indiretamente, neste segmento não produziram ou produzem ideias desvinculadas das condições materiais que 0 cercam, mas em conformidade com a correlação de forças das lutas travadas no interior da sociedade. O método marxiano pressupõe investigar as condições que permitem a existência de um determinado objeto, ou seja, há um deslocamento do plano das ideias para o da realidade concreta em que elas são engendradas.

Os pressupostos de que partimos não são arbitrários, nem dogmas. São pressupostos reais de que não se pode fazer abstração a não ser na imaginação. São indivíduos reais, sua ação e suas condições materiais de vida, tanto aquelas por eles já encontrados, como as produzidas por sua própria ação. Estes pressupostos são, pois, verificáveis por via puramente empírica. (Marx \& Engels, 1984, pp. 26-27)

Dessa forma, nenhuma instituição, seja ela qual for, existe de maneira absolutamente livre e, por isso mesmo, absolutamente marginal frente às determinações sociais. Do mesmo modo, as disciplinas vinculadas aos fundamentos da educação não podem ser pensadas desprovidas de vínculo com a totalidade que compreendem as relações de existência que os homens estabelecem entre si. $O$ objetivo deste trabalho é apontar hipóteses acerca da ausência da epistemologia marxista, e especificamente da produção de Manacorda na formação do pedagogo, fornecendo, então, um conjunto de argumentos capazes de estimular o debate acadêmico.

As análises aqui reunidas procuram contemplar, ao menos três aspectos importantes: o cenário do último decênio marcado pelo aprofundamento da crise estrutural do capitalismo e a educação; a pertinência dos textos de Marx, Engels e Manacorda para a formação de professores; e as ementas da disciplina de História da Educação com suas respectivas referências bibliográficas. 


\section{O aprofundamento da crise estrutural do capitalismo e a hegemonia pós-moderna no âmbito da produção acadêmica}

A partir dos anos 1970, com a acentuada crise estrutural das relações capitalistas, e fundamentalmente nos anos 1980/1990, com a queda do Muro de Berlim (1989) e o fim da experiência do socialismo real na URSS (1991), observa-se o fortalecimento de um momento caracterizado pela crença na descontinuidade da história, no efêmero e no suposto fim dos metarrelatos, dentro dos quais se inclui a epistemologia marxista. Dessa forma, o esporádico passou a povoar os temas de estudo de inúmeros pesquisadores.

Essa "nova" forma de abordagem, que expressa a negação da objetividade, deixou de lado a preocupação com os movimentos que explicam a totalidade concreta. No entanto, não se trata de um movimento isolado do meio material que o produz. Muitos intelectuais anteriormente identificados com o pensamento marxista, se voltaram contra as hipotéticas raízes "autoritárias" de Marx e Engels, convertendo-se ao discurso de "aperfeiçoamento" do mercado e da democracia burguesa, entendida como forma universal, contraposta abstratamente à ditadura do proletariado, que no entendimento de Marx nada mais era que o domínio dos trabalhadores sobre o Estado até o aniquilamento da sociedade de classes. De forma análoga, o mesmo pode ser verificado no campo da formação docente marcado fortemente pelo relativismo epistemológico e cultural.

Em um cenário caracterizado pelas sucessivas crises do capitalismo, o discurso comprometido com a ordem burguesa tenta justificá-la por meio da incapacidade de apreender um conhecimento objetivo. Assim, a "nova ordem" suscitou um movimento que colocou na pauta de muitos intelectuais o discurso do "fim do trabalho", "fim da história" ou da impossibilidade de apreender o conhecimento.

Portanto, a crise de paradigmas que se materializou no âmbito da formação de professores deve ser compreendida em sua gênese marcada pela incapacidade da burguesia de resolver as contradições engendradas pelo capitalismo. Os últimos decênios do século XX foram marcados pela:

(...) chamada crise dos paradigmas. Propõe-se, então, o pluralismo epistemológico e temático e privilegia-se o estudo de objetos singulares. $\mathrm{O}$ aspecto positivo dessa fase, que ainda hoje perdura, é representado pela ampliação das linhas de investigação, pela diversificação teórico metodológica e pela utilização das mais variadas fontes de pesquisa. Segundo alguns estudiosos, porém, o que está havendo é, na verdade, uma fragmentação epistemológica e temática que dificulta a compreensão da totalidade do fenômeno educacional. Muitos deles veem, ainda nessa crise de paradigmas, um grande movimento antimarxista e o abandono da perspectiva 
histórica que privilegia temas como cultura escolar, formação de professores, livros didáticos, disciplinas escolares, currículo, práticas educativas, questões de gênero, infância e, obviamente, as instituições escolares (Nosella \& Buffa, 2005, p. 354).

Dessa forma, a fragmentação epistemológica que dificulta a compreensão da realidade é um fenômeno que expressa os antagonismos de classe e a hegemonia burguesa no campo da educação. Por isso, é fundamental que o pesquisador compreenda que as opções presentes nas epistemologias que orientam as disciplinas são entrelaçadas e condicionadas pelas lutas travadas no interior da sociedade. "Não é possível, portanto, compreender radicalmente a história da sociedade e, consequentemente, a história da educação contemporânea, sem se compreender o movimento do capital" (Saviani, 2005, p. 17).

\section{A pertinência da epistemologia marxiana e de Manacorda para formação de professores}

Levando-se em consideração a importância da produção de Marx e Engels para a compreensão das relações sociais engendradas pelo modo de produção capitalista, Manacorda constitui-se em um autor fiel à ordotoxia marxiana. Para esclarecer o pensamento marxista sobre o ensino, Manacorda parte da análise filológica dos textos de Marx e Engels, explicitando a relação entre educação escolar e sociedade.

(...) o que está em jogo não é manter a todo o custo uma fidelidade ao marxismo ou uma subserviência às ideias de Marx. O que está em causa é verificar em que medida as transformações políticas em curso este início da década de noventa do século 20 autorizam a conclusão de que Marx foi ultrapassado não fazendo mais sentido tomá-lo como referência para 0 estudo dos problemas contemporâneos. (Saviani, 2007, p. 17).

Ora, a atual crise estrutural das relações capitalistas de produção, inaugurada no início dos anos 1970, deixa clara a necessidade de retomar o estudo rigoroso sobre o desenvolvimento de suas contradições. Não se pode perder de vista que o rigor da produção de Manacorda, alicerçada na epistemologia marxiana, se contrapõe aos discursos apologéticos de defesa de uma ordem profundamente desigual.

Parece-me, contudo, que o caminho do futuro seja aquele que o passado nunca soube percorrer, mas que nos mostrou negativo, descortinando suas contradições. E estas foram e são (é preciso repeti-lo?) entre a essencial importância humana da formação do homem e o seu acantonamento de fato como coisa de criança; entre a instrução dos dominantes para o "dizer" intelectual e dos 
dominados para o "fazer" produtivo; entre a exigência de uma formação geral humana e a preparação de cada um para competências distintas (como as do dizer e as do fazer); entre a máxima reverentia que se deve à criança e o perpétuo recurso ao sadismo pedagógico, com as inevitáveis consequências contestadoras; entre a hodierna assunção tendencial de todos numa instituição privilegiada, intelectual, e a sua real exclusão de uma vida plena e sua separação dos adultos; entre a persistente predominância de um ensino lógico-verbal e a necessidade humana, especialmente dos adolescentes de uma vida escolar que não exclua, mas corresponda à sua vida real, quer do corpo quer da mente, com suas atividades artísticas, produtivas e físicas colocadas no mesmo nível das atividades (pseudo)intelectuais. Em suma, a exigência de uma escola que, de lugar de privações, se transforme num lugar e numa época de plenitude de vida. (Manacorda, 1996, p. 360)

Esses aspectos constituem, sem dúvida, um indicador da atualidade do marxismo. O rigor metodológico de Manacorda proporcionou o desvelamento das concepções marxianas a respeito da pedagogia, o que representa um contraponto importante diante das propostas alicerçadas no subjetivismo fragmentário.

Porém, diante das próprias limitações de espaço deste texto, não é possível realizar uma exaustiva análise sobre a importância da produção marxiana e de Manacorda para a educação. Quando reivindicamos a atualidade do primeiro e o rigor metodológico do segundo, o fazemos a partir de uma análise comprometida com a compreensão da educação como expressão da sociedade que a produziu e das contradições geradas pelos antagonismos de classes. Assim, a epistemologia alicerçada no materialismo histórico e dialético mostra-se como uma ferramenta teórica que auxilia na adequada compreensão dos fenômenos sociais.

No entanto, a julgar pelas ementas, objetivos e bibliografia disponibilizados para consulta, estariam os novos professores aptos para compreender a realidade contemporânea a partir de uma práxis articulada com a necessidade de superação? É possível que os futuros docentes, diante das condições materiais de sua formação, compreendam um determinado modo de produção, suas contradições e seus vínculos com o fenômeno educativo? Se Marx e Engels desvelaram as contradições do modo de produção capitalista, que se encontra em plena crise estrutural, por qual razão deveríamos desconsiderar a epistemologia marxista?

Os questionamentos levantados têm por objetivo levantar uma hipótese de trabalho que possibilite novas frentes de investigação que contribuam para o desvelamento das formas precárias de formação de professores não como algo separado da produção da existência.

Não se trata, como na concepção idealista da história, de procurar uma categoria em cada período, mas sim de permanecer sempre o solo da história real (...) Toda concepção histórica, até o momento, ou tem omitido completamente esta base real da história, ou a tem considerado como algo secundário, sem qualquer conexão com o 
curso da história. Isto faz com que a história deva sempre ser escrita de acordo com um critério situado fora dela. A produção da vida real aparece como algo separado da vida comum, como algo extra e supraterrestre. (Marx \& Engels, 1984, pp. 56-58)

O ponto de vista de Marx e Engels apresenta-se como claro e atual até o presente, pois diferencia-se das perspectivas idealistas que consideram "natural" aquilo que é historicamente construído por meio das relações sociais.

Isto posto, a pesquisa com planos de ensino publicados nas páginas eletrônicas dos cursos de pedagogia de Universidades Federais apresenta, obviamente, uma série de restrições, entre as quais, a distância entre o que está prescrito e aquilo que efetivamente se materializa em sala de aula. Ressaltem-se igualmente as dificuldades materiais que professores encontram no desenvolvimento do trabalho docente na academia. Entretanto, se a tarefa é complexa, há que se analisar o levantamento de algumas hipóteses acerca da ausência de Marx e Manacorda, fornecendo assim, um conjunto de argumentos capazes de estimular o debate acadêmico.

\section{Apontamentos sobre a ausência de Marx e Manacorda nos cursos de pedagogia em Universidades Federais}

Um balanço rigoroso sobre os projetos político pedagógicos presentes nos cursos de pedagogia - que escapa inteiramente aos propósitos deste trabalho e que, certamente, levantaria outra ordem de questões -, este balanço provavelmente haveria de demonstrar que as lacunas existentes dificilmente poderiam ser evitadas nas condições materiais que ocorrem a formação do pedagogo.

A formação do pedagogo, assim como toda atividade no âmbito da educação, reflete as contradições presentes nas relações sociais marcadas pelo modo de produção capitalista, em que a mesma alienação produzida pelas relações de trabalho ocorre igualmente na formação de professores: fragmentação do conhecimento e ausência de reflexão. Em outras palavras, subordina-se a educação aos interesses do mercado do capital. Desse modo, o quadro de tendências identificado na pesquisa aponta para práticas que não contribuem para explicar o mecanismo contraditório de funcionamento da sociedade em que se insere o sistema escolar e a escola.

Por isso, não é possível desvincular as escolhas epistemológicas presentes nos cursos presentes na formação de professores da forma pela qual os homens se relacionam na produção da vida. Assim, não nos parece novidade a hegemonia do discurso sedutor da "educação para a cidadania", "do multiculturalismo", "do professor reflexivo", "dos saberes docentes". Transplantadas para a formação de professores, essas proposições manifestam-se na valorização da prática esvaziada de conteúdo e de uma análise que possibilite a compreensão e transformação da 
realidade sócio educativa. Neste cenário, a produção de autores identificados com o pensamento marxista é reduzida.

Buscando atender aos propósitos deste trabalho, vejamos a participação de Manacorda e Marx nas indicações bibliográficas disponibilizadas pelas instituições no quadro 1:

Quadro 1 - Indicação bibliográfica de Manacorda e Marx

\begin{tabular}{|c|c|}
\hline OBRAS & $\begin{array}{l}\text { Indicação nas } \\
\text { referências } \\
\text { bibliográficas }\end{array}$ \\
\hline $\begin{array}{l}\text { Manacorda, M. A. História da Educação: da antiguidade aos } \\
\text { nossos dias. }\end{array}$ & 09 \\
\hline Manacorda, M. A. Princípio educativo em Gramsci. & 02 \\
\hline Manacorda, M.A. Marx e a Pedagogia Moderna & 01 \\
\hline $\begin{array}{l}\text { Manacorda, M.A. (2009) Reflexões sobre história e educação: o } \\
\text { século e as perspectivas para o futuro. In J. C. Lombardi, D. } \\
\text { Saviani, Navegando pela História da Educação brasileira: } 20 \\
\text { anos de HISTEDBR (pp. 13-43). Campinas: Autores Associados; } \\
\text { HISTEDBR. }\end{array}$ & 01 \\
\hline Marx, K. Manuscritos econômicos filosóficos & 08 \\
\hline $\begin{array}{l}\text { Marx, K. (1994). O Capital. Rio de Janeiro: Bertrand Brasil (Vol. } \\
\text { 1, tomo I) }\end{array}$ & 01 \\
\hline Marx, K., \& Engels, F. Manifesto do Partido Comunista & 01 \\
\hline Marx, K. Crítica ao Programa de Gotha & 01 \\
\hline $\begin{array}{l}\text { Marx, K. (1984). História (Grandes Cientistas Sociais, núm. 36). } \\
\text { São Paulo, Ática }\end{array}$ & 01 \\
\hline $\begin{array}{l}\text { Marx, K. (1983). A Mercadoria: Considerações históricas sobre a } \\
\text { análise da mercadoria. In K. Marx, Contribuição à Crítica da } \\
\text { Economia Política. São Paulo: Martins Fontes. }\end{array}$ & 01 \\
\hline $\begin{array}{l}\text { Marx. K., \& Engels. F. (1975). Obras escolhidas (Vol. 2). Madri: } \\
\text { Editoial Ayuso }\end{array}$ & 01 \\
\hline $\begin{array}{l}\text { Marx, K. (1994). O capital: crítica da economia política (14a } \\
\text { edição). Rio de Janeiro: Bertrand Brasil. }\end{array}$ & 01 \\
\hline
\end{tabular}

Fonte: Elaboração do autor.

Os resultados encontrados denunciam o distanciamento da epistemologia marxista da maioria das disciplinas. Assim, o exame dos programas curriculares permitiu contabilizar que, do conjunto de 57 disciplinas que compuseram a amostra: 
a) Trinta e quatro (34) disciplinas são marcadas pela ausência absoluta de qualquer referência aos textos de Marx e Engels;

b) Quarenta e três (43) disciplinas não apresentam nenhuma referência aos textos de Manacorda;

c) Duas disciplinas apresentam formulações em seu ementário com categorias marxianas, mas sem a presença de Marx ou Engels na indicação bibliográfica;

d) Doze (12) disciplinas, apresentam em suas respectivas indicações bibliográficas obras ou autores ligados ao legado de Marx, como é o caso de Mário A. Manacorda.

e) Entre os vinte e quatro cursos (24) de pedagogia pesquisados, nove (09) não indicam a leitura das obras de Marx ou Engels em nenhuma das disciplinas ofertadas.

Diante do quadro apresentado, é importante pontuar algumas questões importantes. Quando se aborda a ausência de uma epistemologia marxista na formação de professores, é necessário ressaltar que não se trata de uma questão meramente teórica, mas sim de uma questão prática. O estudo dos clássicos foi banido de inúmeras disciplinas em detrimento de artigos ou leituras de segunda mão, o que revela o esvaziamento dos cursos de formação. Em uma breve síntese, é possível afirmar que sequer os autores que constituíram matrizes para outras epistemologias são utilizados.

Desse modo, o futuro pedagogo, por sua formação, dificilmente adquire conhecimentos suficientes para uma análise rigorosa sobre os determinantes materiais dos fenômenos educativos e dificilmente compreenderá os critérios e exigências da profissão que escolheu.

Para além das questões elencadas, algumas disciplinas apresentam no ementário elementos que indicam diálogo com a obra marxiana ou com autores identificados com o marxismo. No entanto, o "diálogo" com Marx se faz por meio de outros autores, o que nos parece preocupante na medida em que sua leitura por "segunda mão", expressa uma tendência presente na formação de professores: busca-se aquilo que é mais fácil e rápido, ou seja, um conhecimento pronto.

Assim, concretiza-se um modelo de formação fragilizada no âmbito da investigação científica, que contribui para a desqualificação e esvaziamento do acesso ao conhecimento, reduzindo as atividades acadêmicas ao trabalho simplificado e amparado nas práticas cotidianas. Em outras palavras, trata-se da "[...] prática como fonte de conhecimento por meio da reflexão e experimentação" (Facci, 2004, p. 49).

De fato, o processo de aviltamento do conhecimento pode ser observado nas indicações bibliográficas de diferentes disciplinas. Na disciplina de Sociologia da 
Educação I, ofertada pelo curso de Pedagogia da Universidade Federal do Amazonas verifica-se a seguinte ementa:

Fundamentos das Ciências Sociais. Os clássicos da Sociologia: Dutkheim, Weber e Marx. Relação Educação e Sociedade. Enfoques Teóricos em Sociologia da Educação. O paradigma do consenso e do conflito. Cultura e Educação (Universidade Federal do Amazônas, s.d, p. 32).

Já foi dito que a melhor forma de tomar contato com os autores clássicos é por meio da leitura dos próprios, apesar disso não há na bibliografia indicada nenhum dos autores citados na ementa. Não se trata de um caso isolado. Observese, por exemplo, a seguinte ementa da disciplina Economia Política e Educação, disponibilizada no Projeto Político Pedagógico do curso de Pedagogia da Universidade Federal do Ceará:

A crítica aos pressupostos do liberalismo clássico e econômico. As contribuições de Marx, Engels e Lukács para a análise onto-histórica das leis do movimento da sociedade capitalista: a teoria do valor, da mais-valia e da exploração do trabalho, o fetichismo da mercadoria. O trabalho e a constituição do ser social: a dimensão teleológica do trabalho e a relação objetividade-subjetividade. O trabalho na ordem do capital; a crise estrutural do capital e a barbárie social contemporânea. A educação e a alternativa socialista: para além da educação cidadã (Universidade Federal do Ceará, 2008, p. 33).

Ora, não se trata aqui de reivindicar uma literatura de caráter eminentemente marxiana, mas como abordar "a crítica aos pressupostos do liberalismo clássico" a partir das "contribuições de Marx, Engels e Lukács" sem utilizar seus textos? O mínimo que se pode exigir de um estudo consciencioso da proposição da ementa é que se utilize os autores mencionados. Trata-se, em nossa avaliação, de um fenômeno forjado nos quadros da vida acadêmica, em que a discussão sobre o marxismo se estreitou a ponto de não disponibilizar sua leitura aos discentes. É no quadro de negação dos "clássicos" que compreendemos a ausência de uma epistemologia marxista na formação de professores. E, a julgar pela bibliografia disponibilizada, o conhecimento de segunda mão parece ser o suficiente, o que limita $o$ acesso ao conhecimento científico.

A primeira exigência que deve ser feita ao professor é que ele seja um profissional cientificamente instruído. Somente o conhecimento exato, somente o cálculo exato, o próprio conhecimento baseado na ciência é que deve constituir enquanto instrumento para o professor. (Facci, 2004, p. 186). 
Aqui não podemos deixar de assinalar que o fenômeno analisado só pode ser compreendido a partir do cenário marcado pela hegemonia burguesa, que não ocorre somente no campo material, mas também na produção ideológica. Quanto maior a mercantilização do ensino, incluindo as universidades públicas, maior será a probabilidade de oferta de um conhecimento superficial e aligeirado. Assim, diante do atual cenário, não causa espanto o fato de muitos professores não se identificarem como trabalhadores. No entanto, não se trata de responsabilizar os professores pelas condições em que ocorrem o processo de formação, mas sim de estabelecer a conexão com as condições materiais em que ocorrem. Há que se ter clareza que a ação do homem na história ocorre dentro de determinadas circunstâncias materiais. Por conseguinte, o acesso ao conhecimento é condição necessária para compreender e modificar as circunstâncias nas quais se encontra inserido.

É importante destacar que nesse momento de maior tensionamento das contradições, verifica-se a proliferação de disciplinas com bibliografias desconectadas dos autores que se propõe a estudar. Veja-se, por exemplo, a disciplina de "Filosofia Educacional Moderna e Contemporânea", presente no Projeto Político Pedagógico de Pedagogia da Universidade Federal dos Vales do Jequitinhonha e Mucuri.

\begin{abstract}
Estudo das contribuições dos filósofos e/ou correntes filosóficas modernas e contemporâneas que refletiram sobre problemas pedagógicos ou que forneceram os fundamentos filosóficos da educação ocidental (Universidade Federal dos Vales do Jequitinhonha e Mucuri, 2012, p. 35).
\end{abstract}

Tal qual se verifica em outras instituições, a bibliografia disponibilizada no endereço eletrônico privilegia exclusivamente manuais didáticos, tais como "Filosofia da educação", de Maria L. de Arruda Aranha (1996) e "O que é Filosofia da educação", de Paulo Ghiraldelli (2003). Não se trata de desqualificar as obras dos autores citados, mas de observar uma tendência que privilegia o conhecimento de "segunda mão" em detrimento dos clássicos, contribuindo dessa forma para o aviltamento dos conteúdos. Não se vê um único intelectual representante das "correntes filosóficas modernas ou contemporâneas" na bibliografia disponibilizada.

Outro exemplo pode ser encontrado na Universidade de Dourados, quando se observa a disciplina "Educação e Trabalho".

As relações entre Educação e Trabalho, compreendidas nas formas contemporâneas de organização do trabalho e seus diferentes significados para a juventude brasileira no exercício da cidadania, diante do desenvolvimento das novas tecnologias e novas demandas profissionais. O papel da educação, do professor e da formação continuada nas relações de trabalho (Fundação Universidade Federal da Grande Dourados, 2018, documento não paginado). 
Se na relação entre capital e trabalho há um antagonismo, alimentado pela exploração do trabalhador, que se caracteriza atualmente pela intensificação da produção sustentada pelas novas formas de organização empresarial, poderia a proposta presente na ementa contribuir para a elucidação desses problemas?

Antes de prosseguirmos, é importante ressaltar que

(...) o primeiro pressuposto da existência humana e, portanto, de toda a história, é que os homens devem estar em condições de viver para poder 'fazer história'. Mas para viver, é preciso antes de tudo comer, beber, ter habitação, vestir-se e algumas coisas mais. O primeiro ato histórico é, portanto, a produção dos meios que permitam a satisfação dessas necessidades, a produção da própria vida material, e de fato este é um ato histórico, uma condição fundamental de toda a história, que ainda hoje, como há milhares de anos, deve ser cumprido todos os dias e todas as horas, simplesmente para manter os homens vivos. (Marx \& Engels, 1984, p. 39)

Então, para viver e reproduzir, o homem necessita produzir suas condições de existência pelo trabalho. Entretanto, por meio da ementa disponibilizada, verificase uma inversão idealista: "o papel da educação, do professor e da formação continuada nas relações de trabalho". Ora, a educação materializada na sociedade é fruto das relações de trabalho e não o contrário. Além desse aspecto, é importante ressaltar que as contradições originadas da apropriação privada dos meios de produção nas mãos de poucos geram a exploração do trabalho e impedem a plena realização do desenvolvimento humano.

Poder-se-ia também problematizar a questão a partir das indicações de leitura presentes na disciplina. Observam-se somente três obras: Albornoz (2004), Brasil (1998), Ferretti, Zibas, Madeira, Franco (1994). Ressalte-se, que apenas na bibliografia complementar é possível encontrarmos Frigotto e Kuenzer, que se notabilizaram pela produção na área de Trabalho e Educação a partir de uma epistemologia marxiana. Diante do exposto, questiona-se como trabalhar "as relações entre Educação e Trabalho, compreendidas nas formas contemporâneas de organização do trabalho e seus diferentes significados para a juventude brasileira" sem os pressupostos teórico metodológicos do pensamento marxiano?

Se o questionamento acima colocado possui alguma pertinência, será sem dúvida estimulante considerar os problemas da educação por meio de uma releitura dos textos marxianos em que se coloca organicamente no contexto de uma crítica rigorosa das relações sociais. (Manacorda, 1991)

No entanto, o que se percebe é a desfiguração do legado da produção marxiana de sua perspectiva revolucionária, apresentado em fragmentos pouco conectados entre si. Acrescente-se que um autor como Manacorda, conhecedor das línguas antigas (grego e latim), além do inglês, russo e alemão, tradutor de obras de Marx e Lênin, profundo conhecedor da obra de Gramsci, também é "esquecido" nas indicações de leitura das inúmeras disciplinas pesquisadas. 
Na perspectiva marxiana, é possível inferir que o papel do professor, apesar de ser limitado pelas circunstâncias materiais, se reflete em práxis pedagógica. Uma formação empobrecida, sem acesso à teoria, impossibilita a práxis revolucionária.

$O$ fenômeno descrito, que se apresenta em diferentes instituições, em termos práticos, subtrai da agenda de formação de professores a leitura dos clássicos. Assim, questiona-se que tipo de docente é formado na academia? Um professor sem um profundo conhecimento sobre a sociedade e os fundamentos da educação, isto é

(...) um professor medíocre conseguirá que os alunos sejam mais instruídos, porém não mais cultos; pois o professor desenvolverá apenas a parte mecânica da escola e o aluno sendo um cérebro ativo terá que, com a ajuda do seu ambiente social, desenvolver e organizar os conteúdos. (Gramsci, 1982, p. 132)

As reflexões de Gramsci se estendem igualmente ao processo de formação de professores. É impossível pensar na formação de professores sem o domínio do conhecimento necessário ao seu trabalho. Por isso, é imperativo uma política que articule o conhecimento aprofundado dos conteúdos a serem transmitidos e a forma de ensiná-los como requisito ao pleno desenvolvimento humano, fundamentados na convicção de que a educação é um elemento articulador e promotor da cultura. A crítica ao pensamento hegemônico e a estrutura dominante requer capacidade de "desnaturalização" dos fenômenos sociais e isso não se faz de forma espontânea.

Poder-se-á talvez, neste ponto, que o conformismo social -
justamente porque tão ferreamente determinado pela necessidade
objetiva da 'técnica civil' - possa desmentir toda intenção libertadora,
adquirindo o caráter de uma inevitável determinação socioambiental,
frente à qual toda individualidade e personalidade está destinada a
sucumbir. Na realidade, na concepção de Gramsci, a descoberta de
um princípio objetivo, em vez de negar a responsabilidade individual,
exclui, com mais razão, toda arbitrariedade injustificada no exercício
da inevitável conformação social. A teoria fatalista, segundo a qual
"tudo é justificado pelo ambiente social" e a responsabilidade
individual é absorvida pela responsabilidade social, implica tão
somente em compreender o desenvolvimento histórico, que se
resume em uma contínua "luta" para modificar o que existe.
(Manacorda, 2013, p. 241)

Se o homem é produto das circunstâncias, também é verdade que pode modificar as circunstâncias. Desse modo, faz-se necessário contrapor-se às concepções espontaneístas e relativistas no âmbito da formação docente. A propósito, Marx nos lembra que o educador também é educado:

A doutrina materialista da transformação das circunstâncias e da educação esquece que as circunstâncias têm de ser transformadas pelos homens e que o próprio educador tem de ser educado. Daí que 
ela tenha de cindir a sociedade em duas partes, uma das quais fica elevada acima dela. A coincidência da mudança das circunstâncias e da atividade humana ou transformação só pode ser tomada e racionalmente entendida como práxis revolucionária. (Marx, 1984, p. 12)

Desse modo, o educador antes de exercer sua influência formadora, ele próprio é formado dentro de circunstâncias materiais que reproduzem a lógica do capital. Por isso, faz se necessário a constituição de propostas que aliem a competência técnica ao compromisso político na formação docente por uma questão fundamental: a construção de novas instituições educativas depende do grau de consciência teórica incorporado pelo processo de formação docente.

\section{Considerações finais}

Em um cenário de fortes ataques ao marxismo e a todos que se identificam com o propósito de superação da ordem, os resultados obtidos na pesquisa não causam estranheza. Os cursos de pedagogia consultados, ainda que se verifique a evidência de um certo nível de crítica aos limites impostos pelo capital no processo de transmissão e socialização do conhecimento por meio da educação, assumem o compromisso de adequação da escola às exigências do mercado e a de formação para uma cidadania "abstrata". Não por acaso, observa-se o predomínio de uma crítica fragmentada, de caráter insuficiente para se contrapor ao domínio do capital.

A vitalidade do pensamento de Marx pode ser verificada não somente na continuidade de problemas por ele identificados, mas na sua capacidade de desvelálos por meio de um método rigoroso de apreensão do real. A crise estrutural que vivenciamos sob a regência do capital é um atestado de que o pensamento de Marx continua vivo. Da mesma forma, Manacorda, fiel à ortodoxia marxista, esclarece no campo educacional as contradições que o atravessam.

Porém, seria ingenuidade esperarmos um procedimento radicalmente diferente em se tratando de uma sociedade marcada por uma desigualdade estrutural. As relações capitalistas de produção não possibilitam a socialização plena do conhecimento. Por isso, enfatizamos: não existe uma formação docente neutra diante das determinações materiais da sociedade. $O$ futuro professor não pode isentar-se da compreensão das lutas travadas no interior da sociedade que atravessam a educação. $O$ desafio está em formar professores que acima de tudo tenham compreensão histórica dos fundamentos da educação escolar engendrada em uma sociedade de classes. No entanto, a ausência da compreensão sobre os mecanismos de opressão dessa sociedade empobrece a atividade docente e sua intencionalidade.

Por fim, a defesa de uma epistemologia alicerçada no materialismo histórico e dialético como perspectiva unitária de análise da realidade não autoriza nenhum tipo de dogmatismo ou de negação da importância de que a formação do pedagogo 
contemple o estudo de outras correntes do pensamento. Ao contrário, defende-se aqui a necessidade de uma formação sólida, fundada no estudo do conjunto das obras clássicas que auxiliam na compreensão das diferentes matrizes epistemológicas. No caso da formação do trabalhador da educação, não é suficiente colocar à disposição o conhecimento de "segunda mão"; há que se perseguir a intenção de formar o professor com acesso ao conhecimento culturalmente significativo e imprescindível ao seu ofício.

\section{Referências}

Albornoz, S. (2004). O que é trabalho. São Paulo: Brasiliense.

Brasil (1998). Parâmetros curriculares nacionais: terceiro e quarto ciclos:

Apresentação dos temas transversais. Brasília: MEC/SEF, 1998.

Facci, M. G. D. (2004). Valorização ou esvaziamento do trabalho do professor? um estudo crítico-comparativo da teoria do professor reflexivo, do construtivismo e da psicologia vigotskiana. Campinas, SP: Autores Associados.

Ferretti, C. J., Zibas, D. M. L., Madeira, F. R., \& Franco, M. L. P. B. (Org.). (1994). Novas tecnologias, trabalho e educação: Um debate multidisciplinar (3를 edição). Petrópolis, RJ: Vozes.

Frigotto, G. Educação e a crise do capitalismo real (5a edição). São Paulo: Cortez, 2003.

Gramsci, A. (1982). Os intelectuais e a organização da cultura (C.N. Coutinho, Trad. Rio de Janeiro: Civilização Brasileira.

Manacorda, M. A. (1996). História da educação: Da Antiguidade aos nossos dias. São Paulo: Cortez, 1996.

Manacorda, M. A. (1991). Marx e a pedagogia moderna. Campinas: Autores Associados.

Manacorda, M. A. (2013). O Princípio educativo em Gramsci: americanismo e conformismo. Campinas: Alínea, 2013.

Marx, K., \& Engels, F. (1984). A ideologia alemã. São Paulo: Hucitec.

Marx, K., \& Engels, F. (2007). A ideologia alemã. São Paulo: Boitempo.

Netto Paulo, J. (1998) Prólogo: elementos para uma leitura crítica do Manifesto

Comunista. In: K. Marx, Manifesto do Partido Comunista. São Paulo: Cortez.

Nosella, P., \& Buffa, E. (2005). As pesquisas sobre instituições escolares: O método dialético marxista de investigação. Eccos Revista Científica, 7 (2), 351-368.

Saviani, D. (2007). Prefácio. In M. A. Manacorda, Marx e a pedagogia moderna.

Campinas: Autores Associados.

Saviani, D. Transformações do capitalismo, do mundo do trabalho e da educação. In: J.C. Lombardi et al. (Orgs.), Capitalismo, trabalho e educação (3a edição).

Campinas, São Paulo; Autores Associados.

Fundação Universidade Federal da Grande Dourados (2018). Projeto Político

Pedagógico de Pedagogia. Recuperado de

http://files.ufgd.edu.br/arquivos/arquivos/78/COGRAD/Resolu\%C3\%A7\%C3\%A30\%2

OCEPEC\%20235-2018\%20altera\%20PPC\%20Pedagogia.pdf 
Universidade Federal do Amazônas. Projeto Político Pedagógico (s.d). Recuperado de

http://faced.ufam.edu.br/images/stories/arquivos/projeto\%20pedagogico\%20de\%20p edagogia.pdf

Universidade Federal do Ceará Faculdade de Educação Curso de Pedagogia (2008). Projeto Político Pedagógico. Recuperado de http://www.faced.ufc.br/wpcontent/uploads/2018/09/pp-pedagogia-1.pdf

Universidade Federal dos Vales do Jequitinhonha e Mucuri (2012). Projeto Político Pedagógico de Pedagogia. Recuperado de http://media.ufvjm.edu.br/content/uploads/sites/18/2014/09/Pedagogia-ProjetoPedag\%C3\%B3gico.pdf 